\title{
Crenças sobre compreensão oral em língua estrangeira de alunos concluintes de um curso de Licenciatura em Letras
}

\author{
Fernanda Silva Veloso \\ USP - Pós-Doc CAPES/PNPD \\ fervel1981@gmail.com \\ Douglas Altamiro Consolo \\ UNESP - São José do Rio Preto \\ dconsolo@ibilce.unesp.br
}

\section{Resumo}

Neste artigo objetivamos apresentar e discutir algumas das crenças no tocante à compreensão oral de alunos concluintes de um curso de Licenciatura em Letras com habilitação em Português e Italiano. Os dados foram coletados por meio de questionários aplicados a todos os alunos, $\log s$ e entrevistas realizadas por cinco alunos participantes diretos da pesquisa, observação de aulas, gravações audiovisuais e diários. Para fundamentar a discussão, tomamos como base obras de autores que discutiram o conceito de crenças e a definição da habilidade de compreensão oral. A análise dos dados sugere que parte dos alunos concluintes se mostrou desmotivada e apresentou baixas expectativas no que se refere à competência na compreensão oral devido a diversos obstáculos que encontraram ao longo de sua formação. No entanto, crenças emergentes dos dados, como a importância do insumo visual para a compreensão do texto oral, refletem-se positivamente para o alcance de uma proficiência satisfatória em compreensão oral.

Palavras-chave: Crenças. Compreensão oral. Língua italiana. Formação de professores.

\begin{abstract}
In this article we present and discuss a number of beliefs about listening comprehension among students who were in their last year of a teachers' certification Letters course in Italian and Portuguese. The data were collected by means of questionnaires answered by all the participating students, logs and interviews conducted with five of the participating students, classroom
\end{abstract}


observation, lessons recorded on audio and video, and diaries. The study is supported by a rationale on beliefs and on definitions of listening comprehension as a skill. The analysis indicate that a number of students showed lack of motivation and low expectations about developing oral comprehension skills due to several drawbacks in foreign language learning during their teacher education course. However, other beliefs that emerged from the data, such as the importance of visual aids to help understanding an oral text, seem to have a positive effect towards a satisfactory proficiency level in oral comprehension.

Keywords: Beliefs. Listening comprehension. Italian, Teacher Education.

\section{Introdução}

É sabido que a grande maioria dos discentes, ao ingressar um curso de língua estrangeira (doravante LE), deseja desenvolver, principalmente, as habilidades orais, a saber: produção oral e compreensão oral (doravante $\mathrm{CO}$ ). Com a Língua Italiana (doravante LIt.), que no cenário brasileiro raramente é representada graficamente, ocorre o mesmo fenômeno, isto é, a busca pela fala e pela escuta geralmente se inicia logo no primeiro dia de aula.

Dado o desejo pelo desenvolvimento das habilidades de produção e compreensão orais, muitos alunos novatos já possuem e externalizam suas próprias constatações acerca da aprendizagem de tais habilidades orais. Tais pensamentos e/ou percepções são também conhecidos como crenças que podem ser interpretadas como valores que estão diretamente relacionados à aprendizagem e influenciam diretamente o comportamento do aluno segundo Riley (1997).

Com base no exposto, é importante que o professor de LIt. saiba o que buscam seus alunos e conheça as crenças desses discentes sobre o processo de ensino e aprendizagem da LE, particularmente sobre as habilidades orais, a fim de elaborar, caso necessário, um plano de ação mais efetivo dentro da sala de aula (KERN, 1995).

Este artigo constitui um recorte de uma pesquisa de mestrado (VELOSO, 2007) desenvolvida com alunos de um curso de Licenciatura em Letras, com habilitação em Português e Italiano. No entanto, os resultados aqui apresentados dizem respeito apenas aos dados coletados com a turma de alunos concluintes e tiveram como 
orientadoras as seguintes questões de pesquisa: 1) Quais crenças, em relação à compreensão da LE oral, os alunos têm no término de um curso de Licenciatura em LIt. numa universidade do interior paulista?; 2) Essas crenças podem influenciar o processo de desenvolvimento da competência na CO nessa LE? Como?

Analisamos as crenças dos discentes de um curso de Letras em relação à $\mathrm{CO}$ da LIt., pois notamos que tal habilidade linguística, embora seja "um meio essencial de input linguístico para os estudantes de idiomas" (GOH, 2003, p. 1), tem pouco destaque nos livros didáticos de italiano, bem como nas aulas dessa LE.

Este estudo também se justifica pela pouca quantidade de pesquisas que abordam as crenças sobre a $\mathrm{CO}$ em âmbito nacional. Barcelos (2001) sugere que os estudos sobre crenças investiguem aspectos mais específicos; há vários estudos, segundo a autora, com foco nesse tipo de investigação, mas observamos que nenhum deles tem como objeto as crenças sobre a CO de aprendizes de italiano.

Inicialmente, apresentamos alguns pressupostos teóricos ${ }^{1}$ que nortearam o desenvolvimento desta pesquisa. Em seguida, explicitamos o contexto e os participantes do estudo e a metodologia empregada. Por fim, analisamos e discutimos parte dos dados referentes a uma das fases desta investigação e apresentamos algumas considerações finais e encaminhamentos para pesquisas futuras.

\section{Revisão da literatura}

\subsection{Crenças no processo de ensino e aprendizagem de línguas}

O conceito de crença já foi revisto por vários pesquisadores, o que colaborou para o surgimento de inúmeras definições para tal termo, principalmente quando tratamos de crenças sobre o ensino e a aprendizagem de línguas (BARCELOS, 2004). Diante de tantas conceituações para tal noção, optamos por adotar a de Barcelos (2006, p. 18): "Uma forma de pensamento, como construções da realidade,

${ }^{1} \mathrm{O}$ arcabouço teórico apresentado neste artigo foi atualizado após a publicação da dissertação de mestrado na qual nos baseamos. Autores como Field (2008) e Ableeva (2008) foram acrescentados. 
maneiras de ver e perceber o mundo e seus fenômenos, co-construídas em nossas experiências e resultantes de um processo interativo de interpretação e (re)significação".

Tal definição nos pareceu a mais apropriada para este estudo por estar em consonância com os resultados das análises dos nossos dados. Constatamos que grande parte das crenças tem origem em outras experiências de ensino e aprendizagem e pode sofrer pequenas alterações após ser "interpretada" e "(re)significada".

As crenças sobre aprendizagem de línguas podem também influenciar na motivação do aluno, isto é, se a expectativa inicial ou pré-inicial $^{2}$ do estudante não se concretizar, o aluno se frustra e, por consequência, torna-se desmotivado para o aprendizado da LE (RILEY, 1997; SCHULZ, 1996). Daí a importância, segundo esses autores, do conhecimento das crenças tanto pelos alunos como pelo professor.

Outro motivo citado por Barcelos (2001) para a investigação das crenças é a divergência que pode existir entre o que o aluno espera do processo de ensino e aprendizagem e o que o professor de LE espera desse aluno. Desse modo, "pode ocorrer que uma cultura de aprender a que se prende um aluno para abordar uma língua estrangeira não seja compatível ou convergente com uma abordagem específica de ensinar de um professor" (ALMEIDA FILHO, 2002, p. 13). Segundo Kern (1995), na maioria das vezes há uma discrepância entre o enfoque do professor em sala de aula e o desejo do aluno.

No momento em que o aluno adentra o contexto de ensino leva consigo "uma cultura de aprender, um conjunto de representações, crenças e valores relacionados à aprendizagem que influenciam diretamente seu comportamento". ${ }^{34} \mathrm{O}$ docente, por sua vez, também se

\footnotetext{
${ }^{2}$ Vários teóricos afirmam existir uma relação intrínseca entre os conceitos de crenças e expectativas. De acordo com Scheibe (1970), por exemplo, a expectativa pode ser entendida como um subtipo de crença orientada para o futuro.

3 Todas as traduções concernentes aos excertos de dados e às citações originalmente redigidas em língua estrangeira inclusas neste trabalho são de nossa responsabilidade.

${ }^{4}[\ldots]$ to explore the fit of learner and teacher beliefs and take into account learner opinions of what enhances the learning process.
} 
insere no mesmo ambiente com "um conjunto de representações, valores e crenças que incluem o conhecimento técnico sobre o processo de aprendizagem de língua ${ }^{5 "}$ (SCHULZ, 1996, p. 122). O autor postula ainda que os interesses de ambas as partes, quando compartilhados, devem ser interligados com base no levantamento das crenças, que se estabelecerão no contexto se "intersubjetivadas".

Segundo Tudor (2001, p. 32), "as crenças podem ou não ser formuladas explicitamente, mas constituem a moldura de referência dentro da qual os participantes

avaliam e interagem com o ensino de idioma", 6 o que prova que de fato existe uma profunda influência das atitudes e das crenças do estudante em seu ambiente de aprendizagem (COTTERALL, 1995 apud BERNAT; GVOZDENKO, 2004).

Após termos discorrido sobre o conceito de "crenças", na subseção 2.2 apresentaremos a definição de $\mathrm{CO}$, bem como os fatores que influenciam o desenvolvimento de tal habilidade linguística em sala de aula.

\subsection{Compreensão oral: de habilidade passiva a receptiva}

De acordo com Rivers (1981 apud GILMAN; MOODY, 1984), os adultos gastam a maior parte de seu tempo de comunicação com a escuta $(\mathrm{CO})$, como retratamos na Figura 1.

Embora passemos 50\% do nosso tempo diário de comunicação ouvindo, mesmo que tal habilidade esteja acoplada a outras habilidades linguísticas, foi somente na década de 1980, com o estabelecimento da abordagem comunicativa, que a $\mathrm{CO}$ passou a ser vista como o veículo primário para a aprendizagem de língua (ROST, 2001).

${ }^{5}[\ldots]$ with a set of representations, values and beliefs which include expert knowledge about the language-learning process as well as the operation of the self-access system in question.

${ }^{6}[. .$.$] may or may not be explicitly formulated, but they constitute the$ framework of reference within which participants evaluate and interact with language teaching. 


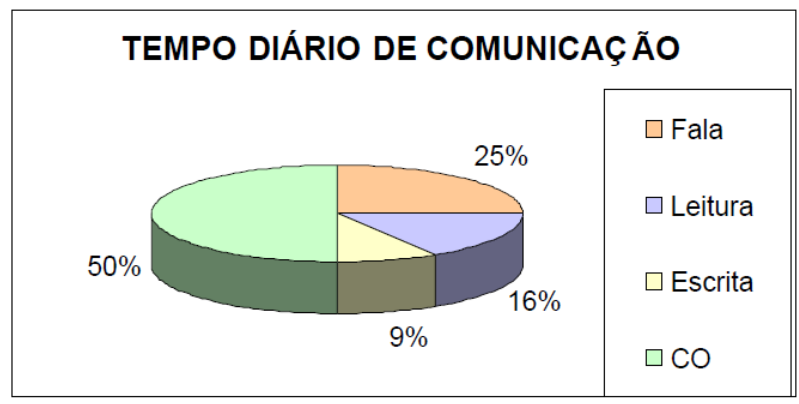

Figura 1. Tempo diário de comunicação de adultos (VELOSO, 2007, p. 33)

Almeida Filho e EL-Dash (2002) alertam que as pesquisas aplicadas sobre o uso e o ensino de línguas não dão a devida atenção aos "múltiplos propósitos pelos quais se ouvem ou leem textos" (p. 19). No caso da CO, apesar de as pesquisas recentes a reconhecerem como uma habilidade importante na aprendizagem de línguas, ela continua a implicar uma das menos entendidas no contexto de ensino e aprendizagem de LE (MUELLER, 1980; MORLEY, 1991).

Tal papel secundário da escuta se deve principalmente ao rótulo "habilidade passiva" que a $\mathrm{CO}$ recebeu durante muitos anos, principalmente na abordagem gramatical. Muitos professores acreditavam que ela não envolvia uma produção ativa, como aquela requisitada pelas habilidades da fala e da escrita. Devido a tal crença, o aprendiz era visto como um "ser passivo", que fazia uso do tipo de CO conhecido por "ouvinte-como-um-gravador" (listener-as-taperecorder), dado o esforço do aluno para memorizar o insumo oral.

Nesse período, as atividades requisitadas dos aprendizes eram principalmente aquelas que testavam a $\mathrm{CO}$, mas não a ensinavam. Como exemplo, podemos citar as tarefas mais utilizadas durante a abordagem de itens isolados, que passou a vigorar no ensino de língua estrangeira a partir da década de 1950. Dentre elas estão as conhecidas identificação fonêmica, paráfrase e avaliação da resposta. Segundo Ableeva (2008), tal abordagem ignora a redundância da língua oral e o contexto de comunicação, que poderiam fornecer informações para que os ouvintes fizessem suas inferências.

Por sua vez, na década de 1970, com a abordagem humanista, surge uma abordagem de ensino da CO conhecida por "integrativa", 
que se destacou por, diferentemente da abordagem anterior, não acessar apenas um elemento por vez durante a escuta da LE. Dentre as técnicas utilizadas estavam o ditado, a tarefa de repetição da sentença, o preenchimento de lacunas, a tarefa de avaliação da sentença e as tarefas de tradução. Embora nessa abordagem se desenvolvam algumas tarefas que de fato permitem aos aprendizes processar o insumo em tempo real, estas, de acordo com Ableeva (2008), não encorajam os aprendizes a relacionar informação linguística ao contexto ou a elaborar inferências.

É somente durante a abordagem comunicativa que as tarefas comunicativas de CO são colocadas em prática nas aulas de LE. Assim, além de processar um insumo oral autêntico, o aprendiz deverá realizar tarefas que simulam situações do mundo real. Tais simulações só são possíveis com o uso do insumo visual acoplado ao insumo verbal oral. Como apontado por Hoven (1997), é a partir do movimento comunicativo e do surgimento das mídias visuais sofisticadas que a compreensão do visual é associada à $\mathrm{CO}$.

Por ser entendida como um processo de compreensão ativo, a $\mathrm{CO}$ nessa abordagem abrange outros dois subprocessos envolvidos simultaneamente: o processo ascendente e o processo descendente, descritos a seguir. $O$ processo ascendente é entendido como a construção de pequenas unidades linguísticas em grandes unidades. De acordo com Nunan (2000), tal processamento ocorre quando ouvimos mensagens orais e segmentamos o texto em sons para formar palavras, as palavras para formar frases e as frases para formar textos.

No processamento descendente, por sua vez, ocorre o inverso, pois a decodificação das mensagens verbais dependerá mais do conhecimento de mundo e do conhecimento do tópico tratado no texto oral. Isso porque usamos um conhecimento que não está diretamente ligado às palavras ouvidas para interpretar o texto oral. São vários os autores que apoiam o uso de ambos os processamentos na compreensão de um texto oral, gerando, assim, o chamado processamento interacional.

Apesar de ser a mais recente, a abordagem comunicativa ou de compreensão da CO também apresenta restrições, visto, por exemplo, que suas tarefas requerem o uso de textos autênticos, que possuem múltiplas interpretações. Como apontado por Field (2008), não é garantido que os aprendizes tornar-se-ão melhores ouvintes de acordo 
com a quantidade de experiências na escuta de textos autênticos em LE. As vantagens dessa abordagem, no entanto, são que os alunos terão uma boa exposição a amostras da L-alvo e desenvolverão a capacidade de criar sentido para o insumo ouvido (FIELD, 2008).

As perspectivas mais atuais para o ensino da $\mathrm{CO}$ apontam para o uso de uma grande variedade de abordagens que podem ser intercambiadas ou combinadas a fim de melhor desenvolver e avaliar a habilidade dos alunos de compreender o discurso oral (ABLEEVA, 2008). Desse modo, é possível usar consciente e adequadamente atividades da abordagem gramatical, por exemplo, quando precisarmos realizar um exercício de percepção de sons da língua-alvo.

Após este panorama da teoria acerca das crenças sobre o ensino e a aprendizagem e a habilidade da $\mathrm{CO}$, trataremos, na próxima seção, da metodologia utilizada na pesquisa.

\section{Metodologia da pesquisa}

Este trabalho enquadra-se no escopo da pesquisa qualitativa de cunho etnográfico, visto que leva em conta o processo de ensino e de aprendizagem na coleta e na análise dos dados, além de retratar eventos do ponto de vista dos atores sociais envolvidos (alunos e pesquisadora).

\subsection{Contexto e participantes}

Nosso estudo foi realizado com uma turma de alunos concluintes do curso de Licenciatura em Letras, com habilitação em Português-Italiano, de uma universidade pública no interior do Estado de São Paulo durante parte do ano letivo de 2005.

A turma escolhida para a pesquisa é composta por 19 alunos, oriundos das redes pública e particular de ensino. Com idades que variam de 21 a 33 anos, esses discentes são, em sua maioria, do sexo feminino. Dentre esses alunos concluintes, a maioria alega que o interesse pela LE é fruto da sonoridade e da musicalidade da LIt., e $21 \%$ citam a ascendência italiana como um dos motivos que desencadearam o interesse pela língua. Quatro alunos se dizem desinteressados pela LE escolhida no início do curso, dois deles 
alegam a falta de utilidade acadêmica da LE, um aluno afirma não gostar de se expressar em LE e o último relata que perdeu o interesse durante o curso de graduação devido ao método tradicional de ensino da LE que, segundo ele, foi adotado no decorrer do curso.

\subsection{Instrumentos de pesquisa}

A fim de mantermos coerência com o cunho etnográfico da pesquisa, optamos por utilizar os seguintes instrumentos de coleta de dados:

Quadro 1. Instrumentos de coleta de dados

\begin{tabular}{|c|c|c|c|}
\hline Quem & $\begin{array}{l}\text { Instrumentos de } \\
\text { pesquisa }\end{array}$ & Quando & Propósitos \\
\hline 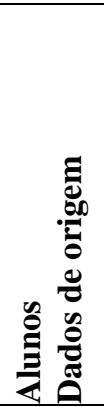 & $\begin{array}{l}\text { Questionário } \\
\text { composto por } \\
\text { respostas pontuais } \\
\text { e abertas. } \\
\text { Entrevista } \\
\text { semiestruturada. } \\
\text { Logs. }\end{array}$ & $\begin{array}{l}\text { Primeiro semestre de } \\
2005 . \\
\text { Final do segundo } \\
\text { semestre de } 2005 \text {. } \\
\text { Ao longo do segundo } \\
\text { semestre de } 2005 \text {. }\end{array}$ & $\begin{array}{l}\text { Inferir as crenças e as } \\
\text { expectativas dos } \\
\text { alunos em relação à } \\
\text { CO por meio de seus } \\
\text { discursos oral e } \\
\text { escrito. }\end{array}$ \\
\hline 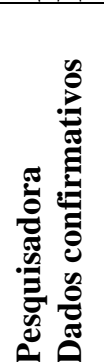 & $\begin{array}{l}\text { Notas de campo. } \\
\text { Gravações em } \\
\text { áudio e/ou vídeo. }\end{array}$ & $\begin{array}{l}\text { Primeiro e segundo } \\
\text { semestres de } 2005 \text {. } \\
\text { Primeiro e segundo } \\
\text { semestres de } 2005 \text {. } \\
\text { Ao longo do segundo } \\
\text { semestre de } 2005 \text {. }\end{array}$ & $\begin{array}{l}\text { Obter dados da } \\
\text { prática de sala de } \\
\text { aula. } \\
\text { Verificar } \\
\text { incoerências. } \\
\text { Registrar os dados. }\end{array}$ \\
\hline
\end{tabular}

Investigamos o problema desta pesquisa sob os pontos de vista da pesquisadora e dos alunos. O princípio da triangulação deu-se entre os tipos de dados analisados, isto é, os dados gerados por diversos instrumentos, aplicados a participantes e pesquisadora com o propósito de possibilitar uma visão mais geral ou global sobre um mesmo 
evento. Para que essa triangulação fosse possível, os dados obtidos por meio dos instrumentos de pesquisa foram divididos, como apontado na tabela, a fim de levantarmos e confirmarmos as categorias de análise.

\section{Análise e discussão dos dados}

A análise das crenças dos informantes da pesquisa foi feita com base nas diretrizes da abordagem contextual (BARCELOS, 2003), uma vez que investigamos as crenças em um contexto específico de ensino e aprendizagem. Esta investigação foi baseada em diferentes ângulos e combinou observações, entrevistas e questionários, embora este último instrumento não seja utilizado na abordagem por nós adotada.

Vale frisar que foi a análise do questionário semiestruturado que nos possibilitou a realização de um levantamento prévio de algumas das crenças que os alunos, IPs e INPs desta pesquisa, têm acerca do processo da CO. Essas crenças relacionadas previamente foram refutadas ou confirmadas pela entrevista realizada com os informantes participantes, pelos logs confeccionados pelos informantes participantes e pelos dados obtidos durante a observação em sala de aula.

Algumas crenças foram identificadas por meio de outros instrumentos que não o questionário semiestruturado, e mesmo nesses casos tais crenças também foram sustentadas pelas informações obtidas pelos outros instrumentos de pesquisa.

Ressaltamos que não foi possível apresentar muitos fragmentos de transcrição de aulas que retratassem as crenças dos alunos quanto gostaríamos porque os alunos informantes pouco se pronunciaram durante as aulas observadas. Ademais, as crenças referentes à $\mathrm{CO}$ dificilmente foram verbalizadas, uma vez que o processamento do texto oral é um processo cognitivo no qual, na maioria das vezes, o aluno "interage consigo mesmo" e com o texto.

\subsection{As crenças dos alunos em relação à aprendizagem da $\mathrm{CO}$}

Abordaremos nesta subseção duas das crenças detectadas que influenciam diretamente o desenvolvimento da habilidade de CO. A 
primeira está relacionada à percepção dos alunos de que a velocidade da fala do nativo é muito rápida, e a segunda contempla o papel que os alunos atribuem ao insumo visual para a compreensão da LE.

\subsubsection{A fala do nativo é rápida}

Ao responderem à pergunta de número 7 ("Você entende/compreende as atividades de compreensão oral apresentadas pelo professor? Por quê?") do questionário aplicado, grande parte dos alunos que em suas respostas apontaram dificuldade para compreender o texto oral disse que a fala do nativo nos áudios das atividades de $\mathrm{CO}$ possuem uma velocidade além do normal.

Considerando tais dados, averiguamos que $82 \%$ dos alunos dizem entender o áudio reproduzido por falantes nativos e $18 \%$ afirmam entender apenas às vezes. Para os últimos, um dos fatores que mais prejudicam a compreensão desse tipo de texto oral é a alta velocidade da fala do nativo. Na sequência, apresentamos alguns excertos do questionário que comprovam as considerações feitas anteriormente:

7) Você entende/compreende as atividades de compreensão oral apresentadas pelo professor? Por quê?

Fragmento 1

1. A3: Algumas vezes é difícil por causa da acústica das salas e da velocidade das falas.

(Questionário, 25 de agosto de 2005.)

Fragmento 2

1. A4: Geralmente. O problema é compreender italianos falando com velocidade rápida.

(Questionário, 25 de agosto de 2005.)

Fragmento 3

1. A17: Nem sempre, porque os diálogos muitas vezes são rápidos e o som não é muito bom.

(Questionário, 25 de agosto de 2005.) 
Considerando as afirmações apresentadas anteriormente, apuramos que a fala do nativo é considerada um elemento complicador durante o processo de $\mathrm{CO}$ pelos discentes. Esse é um dos fatores que, segundo Brown e Yule (1983) e Rubin (1994), tornam a CO difícil. Outros elementos, como a quantidade de interlocutores, o tipo de sotaque e as variações dialetais, também influenciam na compreensão de um texto.

Com o propósito de confirmar as asserções dos alunos encontradas nas respostas dadas ao questionário, buscamos outros indícios da existência da crença de que "a fala do nativo é rápida" nos dados fornecidos pelos demais instrumentos de coleta. Tais opiniões são expostas nos fragmentos a seguir:

\author{
Fragmento 4 \\ A18: Che cosa significa" ((continuam ouvindo)) \\ P2: Dai! \\ A18: Professora (+) é dificil (+) hein" pelo amor de deus \\ P2: Questo professore Simone (incomp.) ah" \\ (Transcrição de aula ilustrativa, 7 de novembro de 2005.)
}

\title{
Fragmento 5
}

1. A12: Algumas coisas consigo entender, mas a impressão que tenho é de que o nativo fala

2. muito rápido. (Questionário, 25 de agosto de 2005.)

\section{Fragmento 6}

1. A15: Não. Um nativo fala muito rápido para o meu nível de CO. (Questionário, 25 de agosto de 2005.)

Os dados referentes aos alunos citados nos fragmentos 4, 5 e 6 apontam para uma dificuldade desses discentes em compreender a fala do nativo porque julgam-na rápida demais. Por exemplo, no excerto 4 notamos que a aluna A18 manifesta seu espanto ao ouvir um trecho de uma entrevista feita com um falante nativo. Esse tipo de manifestação é frequente em sala de aula, visto que os estudantes afirmam não compreender bem a fala do nativo. Nesse caso específico, observamos que a má acústica da sala de aula e a qualidade do áudio foram agravantes que contribuíram para a incompreensão da fala do nativo. 
Do grupo todo, somente o aluno A3 teve a oportunidade de entrar diretamente em contato com falantes nativos na Itália. Entretanto, em sua entrevista observamos que ele continua a afirmar que a LIt. é falada de maneira mais rápida do que a Língua Portuguesa, como conferimos no excerto 7 :

Fragmento 7

1. A3: Lá ((na Itália)) é bem mais rápido (+) eles falam muito mais rápido /../ tem uns que

2. até dá (+) tens uns que são mais rápidos $(+)$ mas como a gente num $(++)$ num $(+)$ num:: não

3. tem acho que toda aula pelo menos uma vez por semana (+) eu acho que dál sente uma

4. diferença (+) antes de eu ir pra Itália (+) eu sentia bastante $(+)$ mais dificuldade $(+)$ depois

5. que eu vim de lá eu me acostumei (+) eles andam muito rápido $(+)$ falam muito rápido $(+)$

6. muito rápido, rápido (+) então você acostuma um pouco (+) então hoje quando eu ouço dá

7. pra entender melhor (+) mas não tudo. (Entrevista, 25 de novembro de 2005.)

Dada a resposta de A3-4 na entrevista (fragmento 7), é possível pensar que ele não tivesse refletido sobre sua LM e sobre a LE enquanto esteve na Itália. No entanto, constatamos, em outro momento da entrevista, que A3-4 possui uma opinião que não condiz com aquela apresentada no questionário (fragmento 1), como conferimos no fragmento 8:

Fragmento 8

1. A3: É:::(+) é difícil é e a gente vê como estrangeiro (++) pra eles deve ser normal (+) mas a

2. impressão que eu tive é que:: e que eu tenho às vezes do diálogo é que eles nem respiram /.../

3. Né" talvez é a impressão de (+) de estrangeiro talvez (incomp.) seja menos pra falar.

(Entrevista, 25 de novembro de 2005.)

No trecho anterior podemos notar que o aluno se dá conta de que a fala do nativo italiano é rápida apenas do ponto de vista do 
ouvinte estrangeiro, ao passo que tem uma velocidade normal para os nativos, assim como ocorre em sua língua materna.

Os IPs A4 e A2 possuem uma opinião diferente daquela de seus colegas, dado que, ao afirmarem que o nativo fala rapidamente, refletem também sobre seus próprios comentários e percebem que sua opinião pode ser apenas uma impressão, e não uma constatação propriamente dita. Notamos essa reflexão nos fragmentos 9 e 10 a seguir:

Fragmento 9

1. A4: /.../ o áudio realmente pra mim é complicado porque eles falam così fretta, muito

2. rápido e aí:: /.../ Eu não sei se é impressão (+) se é a gente que:: se a gente fala o italiano na

3. velocidade que a gente fala o português (+) ou se a gente fala MAIS devagar /.../ por ser

4. lingua estrangeira eu acho que a gente acaba falando com mais VAGAR: até porque a gente

5. tem que pensar (+) pra falar (+), porque não é natural. l.../ Aí depende $(+)$ se tá no

6. restaurante (+) dá pra compreender (+) se é uma situação de briga (+) não entende (+) né" é

7. mais rápido que o normal. (Entrevista, 3 de novembro de 2005.)

Fragmento 10

1. A2: Do diálogo él (+) do Linea é porque é rápido demais que eles falam então tem que

2. ouvir muitas vezes pra/ sempre fica alguma: (+) que eles fazem um truncamento (+) alguma

3 coisa assim (+) não sei que esse eu num::/ (+) de repente você pensa que é uma palavra e é

4. outra /.../

5. A2: Mas assim:: é:: (+) a questão da rapidez que eles falam $(+)$ eles falam::: num::: ritmo

6. normal de fala (+) não é"

7. PQ: /... 'Em ritmo normal de fala PRA ELE',

8. [

9. A2: Do:: é pra ele

10.PQ: 'Pra gente que ouve você acha que:"' 
11.A2: É difel é::: é rápido (Entrevista, 25 de novembro de 2005.)

Assim como na entrevista, um comentário de A4 em um de seus logs (fragmento 11) também demonstra sua reflexão acerca da crença em questão:

\section{Fragmento 11}

1. O italiano do "ascolto", um professor, falava com uma velocidade bastante rápida. /.../

2. Preciso, agora, acostumar os meus ouvidos a diálogos como este (inclusive em língua

3. materna). Se em vez de um italiano fosse um brasileiro do interior de São Paulo que falasse

4. naquela velocidade e com aquela "entoação", certamente eu também não o compreenderei.

(Log de A4, 7 de novembro de 2005.)

Ao deparar-se com sua própria crença, acreditamos que os alunos a questionam devido à percepção de que a rapidez da língua varia de acordo com o ponto de vista do sujeito, se nativo ou estrangeiro, e também com a situação em que tal língua é usada. $\mathrm{O}$ falante, em um seminário ou palestra, muito provavelmente organizará melhor sua fala e consequentemente utilizará mais pausas, o que garante um maior entendimento do insumo oral. O mesmo, no entanto, não acontece em uma situação do cotidiano familiar, em que os falantes não se preocupam com a polidez ou a vagarosidade do discurso.

Richards e Schmidt (1983) sustentam que o ato da fala pode afetar consideravelmente a maneira como entendemos as mensagens. Aos fatores que afetam a compreensão, conhecidos como fatores médios, é possível incluir a velocidade de recebimento do texto, que é a impressão que o ouvinte possui de uma fala ser mais rápida, como a fala do nativo, ou mais lenta, como a fala do professor. Os autores ainda explicam que essa impressão é resultado da quantidade de pausas que o falante usa em seu discurso. Assim, se as pausas são eliminadas, como em muitas situações da fala do nativo, cria-se a ideia de que a fala é rápida. 
Diante do exposto, pensamos ser necessário que o professor ajude seus alunos a vencer os "elementos complicadores da CO" para que se tornem bons ouvintes a partir da interação com o texto, com o contexto de sua produção, com a tarefa e com o contexto de sala de aula.

Na subseção a seguir passamos a algumas considerações sobre a visão dos informantes sobre a habilidade da $\mathrm{CO}$, com suas ponderações sobre o papel do insumo visual na compreensão dos textos orais em LE.

\subsubsection{O insumo visual facilita a compreensão de textos orais}

A fim de processar a fala do nativo, alguns alunos utilizam com frequência o insumo visual presente nas atividades de $\mathrm{CO}$. Por meio da análise dos nossos dados, verificamos que os alunos possuem a crença de que tal insumo facilita a $\mathrm{CO}$.

Os alunos, muitas vezes, apoiam-se em gestos, ilustrações e expressões faciais para compreender o insumo oral recebido. Eles citaram fontes de insumo visual, além do insumo visual verbal, que auxiliam no processamento das mensagens linguísticas orais, como podemos observar no excerto a seguir:

\section{Fragmento 12}

1. A4: Ah e eu me lembro de um ascolto lá do $C D(+)$ tem as imagens (+) isso ajuda /.../é (+)

2. e perde no ascolto

3. $P Q$ : 'Você acha que perde",

4. A4: Ah sim (+) porque no ascolto é só ouvir (+) não vê nem a boca mexendo $(+)$ né"

5. $(($ risos $))$ /.../ traz poucas $(+)$ mas/ mas traz $(+)$ isso ajuda claro $(+)$ claro /.../ vixe $(+)$ porque

6. você dá uma olhada antes assim (+) aquela olhadinha já dá pra entender muita coisa ((risos))

(Entrevista, 3 de novembro de 2005.)

Na primeira parte do fragmento 12 o aluno A4 assinala que nas atividades de compreensão oral (ascolto) do LD usado em sala de aula não se tem contato com as expressões faciais do falante, o que facilitaria a compreensão. Ainda de acordo com A4, o LD não possui 
muitas figuras no espaço destinado às habilidades orais, mas as poucas que traz, segundo ele, facilitam a compreensão do insumo oral.

O posicionamento da academia ainda não é unânime sobre o uso de insumo visual nas atividades de $\mathrm{CO}$. Enquanto a maioria afirma que tal tipo de insumo pode facilitar o entendimento do texto oral, uma minoria prega que o insumo visual, como o vídeo, pode atrapalhar a compreensão.

Berber-Sardinha (1992 apud BERBER-SARDINHA, 1997), por exemplo, afirma que as imagens parecem contribuir para melhorar a CO. No entanto, o autor ressalta que "há indícios na literatura de que parece haver uma melhora na compreensão quando as imagens concordam com a informação narrada" (BERBER-SARDINHA, 1997, p. 179). Se o aluno escuta um texto sobre determinado tema é importante que o mesmo enfoque seja dado à ilustração, como comenta A4, ao afirmar que: “/.../ aquela olhadinha já dá pra entender muita coisa".

Ao fornecer pistas contextuais importantes para a realização da $\mathrm{CO}$ e agir como organizador eficiente, aumentando a compreensão do estudante e a retenção do material, o suporte visual é uma ajuda à compreensão de textos (ANDERSON; LYNCH, 1988; RUBIN, 1994; OMAGGIO, 1979 apud COLE et al., 1995).

Muitos alunos, durante a observação das aulas, demonstraram mais segurança em realizar as atividades de $\mathrm{CO}$ acompanhadas de figuras. Além disso, os gestos e as expressões faciais da docente durante sua fala em LE pareciam facilitar a compreensão pelos alunos.

Diante de tais constatações, podemos afirmar que a crença apresentada por esses alunos se comprova. No entanto, quando o insumo visual é um vídeo, a compreensão do texto oral pode ser prejudicada de acordo com alguns pesquisadores.

O aluno A-4, durante a entrevista, afirmou que "o ascolto é só ouvir (+) não vê nem a boca mexendo $(+)$ né"”. Assim, parece acreditar que a leitura labial dos interlocutores poderia facilitar a compreensão do insumo verbal em um vídeo por exemplo. Alguns autores, entretanto, sustentam que esse tipo de insumo visual poderia distrair os ouvintes, piorando seu desempenho (READ, 2002).

Segundo Read (2002), tal impasse só pode ser solucionado se o professor levar em conta o público-alvo ao qual destinará a atividade, visto que a ajuda, ou não, do vídeo na $\mathrm{CO}$ dependerá do estilo de 
aprendizagem do aluno ouvinte. Se ele não estiver habituado a processar insumos oral e visual ao mesmo tempo, a inclusão do canal visual à atividade pode não alterar seu desempenho.

O vídeo, outro tipo de insumo visual, é utilizado já há algumas décadas, segundo Wagner (2008), para possibilitar ao ouvinte processar o insumo oral. Torresan (2004) sustenta ainda que a língua acompanhada da imagem tende a ser memorizada mais facilmente.

Além de contribuir para um melhor desempenho do aluno em atividades de $\mathrm{CO}$, os vídeos reproduzem, de certa forma, uma interação real, dado que no dia a dia o ouvinte quase sempre tem contato tanto com o insumo verbal quanto com o visual quando escuta a LE.

As duas crenças apontadas pelos informantes podem, de fato, interferir no processo de desenvolvimento da competência na $\mathrm{CO}$ em LIt., visto que, dependendo da maneira como encaram o curso de Licenciatura em Letras e seu papel nele, os alunos se assumem como responsáveis, ou não, por atingir a proficiência desejada.

\section{5 À guisa de conclusão}

Este estudo teve como propósito inicial apresentar e discutir as duas principais crenças de alunos concluintes do curso de Licenciatura em Letras com habilitação em Português e Italiano de uma universidade pública paulista, com relação à $\mathrm{CO}$, a fim de verificar suas possíveis contribuições para o desenvolvimento desta habilidade oral.

As duas crenças que constatamos com os estudantes foram: "a fala do nativo é rápida" e a relação entre "o insumo visual facilita a CO”. A primeira delas parece ter como um de seus reforços a fala facilitadora do professor e o insumo simulado fornecido pelo livro didático utilizado em sala de aula. A segunda crença favorece bastante a compreensão dos textos orais, visto que os alunos demonstraram fazer uso dos elementos paratextuais durante o processo, de forma que fosse facilitado o entendimento.

Quando afirmam que a fala do nativo é rápida, acreditamos que os alunos possuem uma falsa sensação acerca da PO do falante nativo. Além disso, a fala do nativo é comparada à fala facilitadora do professor, que é permeada por pausas e, consequentemente, mais 
facilmente compreendida (RICHARDS; SCHIMIDT, 1983). Tal dificuldade, muitas vezes, impede os alunos, ao "amedrontá-los", de manter contato com textos autênticos fora da sala de aula, o que poderia contribuir para a aprendizagem da língua, bem como para uma boa proficiência na $\mathrm{CO}$. Como exemplo, podemos citar a preferência de alguns alunos por assistir a filmes com a legenda ou o áudio em português por receio, ou até mesmo por comodismo, de não entenderem as falas em LE.

Acreditamos que todo tipo de insumo visual realmente facilita e auxilia a compreensão na LM e na LE. Desse modo, os alunos que o utilizam como apoio durante o processo de $\mathrm{CO}$ terão maior chance de obter sucesso neste tipo de atividade (OMAGGIO, 2000; BERBERSARDINHA, 1992 apud BERBER-SARDINHA, 1997).

É realmente importante que algumas orientações sejam oferecidas aos docentes que trabalham em cursos de formação de professores de LE para lidar com as crenças dos alunos. No entanto, pensamos também que é importante que o aluno mestre adote uma postura crítico-reflexiva durante sua formação inicial e continuada com o objetivo de tornar-se autônomo a ponto de desenvolver sua competência linguística igualmente fora do contexto de sala de aula.

Tornando-se autônomos, é muito provável que os discentes, durante o processo de ensino e aprendizagem da LE, desenvolvam sua competência linguístico-comunicativa. Assim, é importante que o aluno se torne responsável por sua própria aprendizagem e a partir daí descubra seu estilo de aprender a LE. À instituição de ensino e aos professores compete a tarefa de propiciar condições para que essa aprendizagem aconteça.

Com este estudo pretendemos contribuir para o entendimento de como as crenças referentes à $\mathrm{CO}$ de alunos concluintes de um curso de Licenciatura em Letras com habilitação em Língua Portuguesa e LIt. podem influenciar o desenvolvimento dessa habilidade linguística.

Sugerimos pesquisas que foquem mais apuradamente o papel específico do insumo visual (marcas tipográficas, gestos, fotos, ilustrações, expressões faciais e corporais) nas atividades de $\mathrm{CO}$ a fim de detectar os benefícios potenciais que este facilitador pode trazer ao processo de compreensão do texto oral, bem como ao alcance da proficiência nesta habilidade. 
No tocante às crenças, consideramos que um trabalho que buscasse focar não somente as crenças dos alunos acerca da CO mas também as do professor e os colocasse em contato com esses dados seria de grande importância.

Os encaminhamentos aqui sugeridos têm por objetivo incentivar a continuidade das pesquisas sobre a $\mathrm{CO}$ e colaborar com a compreensão das crenças que influenciam o processo de compreensão de textos orais, além de proporcionar um maior conhecimento desta habilidade.

\section{Referências}

ABLEEVA, Rumia. Listening comprehension in foreign language instruction. CALPER Professional Development Document n. 0810, 2008. University Park: The Pennsylvania State University, Center for Advanced Language Proficiency Education and Research.

ALMEIDA FILHO, José C. P. Dimensões comunicativas no ensino de línguas. 3. ed. Campinas: Pontes, 2002.

ALMEIDA FILHO, José C. P.; EL-DASH, Linda G. Compreensão de linguagem oral no ensino de língua estrangeira. Horizontes de Linguística Aplicada, v. 1, n. 1, p. 19-37, 2002.

ANDERSON, Anne; LYNCH, Tony. Listening. Oxford: Oxford University Press, 1988.

BARCELOS, Ana M. F. Metodologia da pesquisa das crenças sobre aprendizagem de línguas: estado da arte. Rev. Brasileira de Linguística Aplicada, v. 1, n. 1, p. 71-92, 2001.

- Researching beliefs about SLA: a critical review. In: KALAJA, Paula; BARCELOS, Ana M. F. (Ed.). Beliefs about SLA: New research approaches. Dordrecht: Kluwer Academic Publishers, 2003. p. 7-33.

. Ser professor de inglês: crenças, expectativas e dificuldades dos alunos de letras. In: VIEIRA-ABRAHÃO, Maria H. (Org.). 
Prática de ensino de língua estrangeira: experiências e reflexões. Campinas: Pontes, ArteLíngua, 2004. p. 11-30.

- Cognição de professores e alunos: tendências recentes na pesquisa de crenças sobre ensino e aprendizagem de línguas. In: BARCELOS, Ana. M. F.; VIEIRA-ABRAHÃO, Maria H. (Org.) Crenças e ensino de línguas: foco no professor, no aluno e na formação de professores. Campinas: Pontes Editores, 2006. p. 15-42.

BERBER-SARDINHA, Antonio P. Proficiência e compreensão de telenotícias em língua estrangeira. Delta, v. 13, n. 2, p. 177-190, 1997.

BERNAT, Eva; GVOZDENKO, Inna. Investigating Vietnamese ESL learners' beliefs about language learning. EA Journal, v. 21, n. 2, 2004.

<http://www.englishaustralia.com.au/index.cgi?E=hsshowjnl\&efile=ad $\min \& M=\operatorname{art} \& X=$ getdo $c \& L e v 1=5 \& L>$. Acesso em: 20 jan. 2006.

BROWN, Gillian; YULE, George. Teaching the spoken language: an approach based on the analysis of conversational English. Cambrige: Cambridge University Press, 1983.

COLE, Steven P.; HERRON, Carol.; HANLEY, Julia. Using video as an advance organizer to a written passage in the FLES classroom. The Modern Language Journal, v. 79, n. 1, p. 57-65, 1995.

FIELD, John. Listening in the language classroom. Cambridge: Cambridge University Press, 2008.

GILMAN, Robert A.; MOODY, Loranna M. What practitioners say about listening: research implications for the classroom. Foreign Language Annals, v. 17, n. 4, p. 331-334, 1984.

GOH, Christine C. M. Ensino da compreensão oral em aulas de idiomas. Tradução: Rosana Sakugawa Ramos Cruz Gouveia. São Paulo: Special Book Services Livraria, 2003.

HOVEN, Debra. Listening and viewing comprehension: theory and applications. In: Improving the management of flow of control 
in computer-assisted listening comprehension tasks for second and foreign language learners. 1997. Unpublished doctoral dissertation, University of Queensland, Brisbane 1997. p. 75-129.

KERN, Richard G. Students' and teachers' beliefs about language learning. Foreign Language Annals, v. 28, n. 1, p. 71-92, 1995.

MORLEY, Joan. Listening comprehension in second/foreign language instruction. In: CELCE MURCIA, Marianne. Teaching English as a second or foreign language. 2nd. ed. Boston: Heinle e Heinle Publishers, 1991.

MUELLER, Gunther A. Visual contextual cues and listening comprehension: an experiment. The Modern Language Journal, v. 64, n. 3, p. 335-340, 1980.

NUNAN, David. Communicative approaches to listening comprehension. In: —. Language teaching methodology: a textbook for teaches. London: Longman, 2000. p. 17-38.

OMAGGIO, Alice. A proficiency-oriented approach to listening and reading. In: - Teaching language in context. 3rd. ed. Boston: Heinle, 2000. cap. 5, p. 176-225.

READ, John. The use of interactive input in EAP listening assessment. Journal of English for Academic Purposes, v. 1, n. 2, p. 105-119, 2002.

RICHARDS, Jack. C.; SCHMIDT, Richard. W. (Eds.). Language and communication. Harlow: Longman, 1983.

RILEY, Philip. The guru and the conjurer: aspects of counseling for self-access. In: BENSON, Phil.; VOLLER, Peter. (Eds.) Autonomy and independence in language learning. New York: Longman, 1997. p. 114-131.

ROST, Michael. Listening. In: CARTER, Ronald.; NUNAN, David. (Eds.) The Cambridge guide to teaching English to speakers of other 
languages. United Kingdom: University Press Cambridge, 2001. p. 713.

RUBIN, Joan. A review of second language listening comprehension research. The Modern Language Journal, v. 78, n.2, p. 199-221, 1994.

SCHEIBE, Karl E. Beliefs and values. New York: Holt, Rineharan Winston, 1970.

SCHULZ, Renate A. Focus on form in foreign language classroom: students' and teachers' views on error correction and the role of grammar. Foreign Language Annals, v. 29, n. 3, p. 343- 364, 1996.

TORRESAN, Paolo. Il video in classe. Didattica \& Classe Plurilingue, n. 8, p. 1-2, 2004.

TUDOR, Ian. The dynamics of the language classroom. Cambridge: Cambridge University Press, 2001.

VELOSO, Fernanda S. Crenças, expectativas e o papel do insumo na compreensão oral de língua italiana dos alunos de um curso de licenciatura em Letras. 2007. Dissertação (Mestrado em Estudos Linguísticos) - Instituto de Biociências, Letras e Ciências Exatas, Unesp, São José do Rio Preto, 2007.

WAGNER, Elvis. Video listening tests: what are they measuring? Language Assessment Quarterly, v. 5, n.3, p. 218-243, 2008.

Submetido em: 03/06/13

Aceito em: 04/04/14

Title: Beliefs about listening comprehension in foreign languages among graduating students in a Letters course 